\title{
Thermal Interface Evaluation of Heat Transfer from a Pumped Loop to Titanium-Water Thermosyphons
}

\author{
Donald A. Jaworske ${ }^{1}$ \\ NASA Glenn Research Center, Cleveland, Ohio, 44135 \\ James L. Sanzi ${ }^{2}$ \\ Sest Inc., Cleveland, Ohio, 44135 \\ Marc A Gibson ${ }^{3}$ \\ Sierra Lobo, Inc, Cleveland, Ohio, 44135 \\ and \\ Edward A. Sechkar ${ }^{4}$ \\ ASRC Aerospace Corporation, Cleveland, Ohio, 44135
}

\begin{abstract}
Titanium-water thermosyphons are being considered for use in the heat rejection system for lunar outpost fission surface power. Key to their use is heat transfer between a closed loop heat source and the heat pipe evaporators. This work describes laboratory testing of several interfaces that were evaluated for their thermal performance characteristics, in the temperature range of 350 to $400 \mathrm{~K}$, utilizing a water closed loop heat source and multiple thermosyphon evaporator geometries. A gas gap calorimeter was used to measure heat flow at steady state. Thermocouples in the closed loop heat source and on the evaporator were used to measure thermal conductance. The interfaces were in two generic categories, those immersed in the water closed loop heat source and those clamped to the water closed loop heat source with differing thermal conductive agents. In general, immersed evaporators showed better overall performance than their clamped counterparts. Selected clamped evaporator geometries offered promise.
\end{abstract}

\section{Nomenclature}

$\Delta T=$ temperature difference between closed loop heat source and evaporator

$A \quad=$ evaporator surface area

cm = centimeter

$C_{p} \quad=$ heat capacity

$d T=$ temperature difference across gas gap calorimeter

$K=$ Kelvin

$k W_{e} \quad=$ kilowatt, electric

$k W_{t} \quad=$ kilowatt, thermal

$k / L=$ loop - evaporator interface conductance

$m \quad=$ meter

$\dot{m} \quad=$ mass rate of flow

${ }^{1}$ Physicist, Space Environment and Experiments Branch, 21000 Brookpark Rd., Cleveland, Ohio, AIAA Member.

${ }^{2}$ Heat Transfer Engineer, 21000 Brookpark Rd., AIAA Member.

${ }^{3}$ Mechanical Test Engineer, 21000 Brookpark Rd., Cleveland, Ohio, Non-Member.

${ }^{4}$ Mechanical Engineer, 21000 Brookpark Rd. Cleveland, Ohio, Non-Member 


$\begin{array}{ll}N \cdot m & =\text { newton meter } \\ O . D . & =\text { outside diameter } \\ Q & =\text { calculated throughput, watts } \\ W & =\text { watt }\end{array}$

\section{Introduction}

fission surface power installation is envisioned as an option for the lunar surface to provide additional power for lunar outpost operations. ${ }^{1-3}$ Conceptually, heat from a reactor would be utilized to power several Stirling covertors to generate electricity. For a $40 \mathrm{~kW}_{\mathrm{e}}$ installation, radiators would be needed to dissipate approximately $140 \mathrm{~kW}_{\mathrm{t}}$ of waste heat. ${ }^{4}$ The radiators are envisioned to operate at a temperature near $400 \mathrm{~K}$. A closed loop system would deliver heat to the radiator panels through fluid flow, and utilizing vertical radiators would enable two-sided heat rejection. One long term issue for radiators is micrometeoroid impact damage. Expected number of impacts increases with area and time. The cumulative annualized number of hits (in $\mathrm{m}^{2} \cdot \mathrm{yr}$ ) with sufficient kinetic energy to rupture a radiator panel fluid line is $0.002 \mathrm{hits} / \mathrm{m}^{2} \cdot \mathrm{yr}$ at one astronomical unit. ${ }^{5}$ Hence, a panel on the order of 180 $\mathrm{m}^{2}$ over 10 years would have 3.6 hits of sufficient kinetic energy to damage fluid flow. One design solution to mitigate the risk of rupturing a fluid line from a micrometeoroid impact is to utilize multiple heat pipes to deliver heat across the span of the panel and to provide redundancy in the event of a single heat pipe failure. Also planned for the heat rejection system is the use of high thermal conductivity face sheets. The high thermal conductivity face sheets enable more efficient heat distribution across the face of the panel. In the event of a micrometeroid strike, the high thermal conductivity face sheet helps to distribute the heat around the damaged areas. ${ }^{6}$

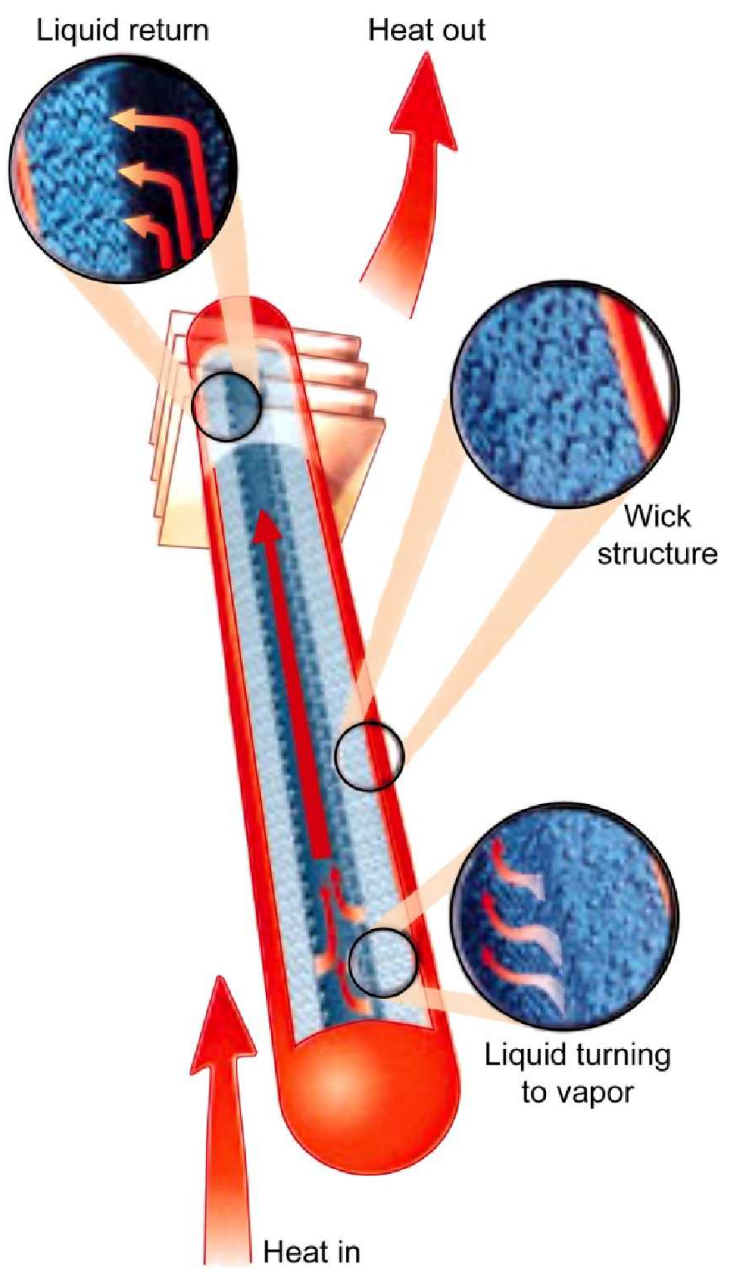

FIGURE 1. Illustration of a thermosyphon. 
Heat pipes are efficient heat dissipation and heat spreading devices. Thermosyphons are a subset of heat pipes which operate in a gravity field. A thermosyphon in its simplest form is a passive two-phase heat transfer device in a sealed tube, as shown in Figure 1. The evaporator region of the thermosyphon is in thermal contact with the heat source. The envelope of the heat pipe is typically made of a high thermal conductivity material and transports the heat to the liquid inside. The only fluid inside the thermosyphon is the working fluid in equilibrium with its own vapor. Liquid in the evaporator region evaporates and is transported to the other end of the pipe where the vapor condenses to release the latent heat to the tube wall. A thermosyphon may or may not be equipped with a wick in the condenser. The condensed fluid is returned to the evaporator region by capillary action (in the presence of a wick) and by gravity (in the absence of a wick). The device is closed and passive.

In this paper, heat exchange from a closed loop heat source to the evaporator of a thermosyphon was investigated. The evaporator section was either immersed in the closed loop heat source, with the closed loop heat source fluid delivering the heat to the evaporator through the evaporator wall, or the evaporator section was clamped adjacent to the closed loop heat source, with the closed loop heat source delivering heat to the evaporator wall via conduction through the clamshell arrangement of hardware surrounding the evaporator. Essentially identical thermosyphons were either immersed in the closed loop heat source or clamped adjacent to the closed loop heat source, and the wattage transported from the closed loop heat source through the heat pipe and out through the condenser was carefully measured by a surrounding calorimeter. Thermocouples measuring temperature difference between the closed loop heat source and the evaporator section of the heat pipes, along with the flow through the calorimeter as measured by a calibrated flow meter, were used to obtain thermal conductance through the immersed or clamped interface.

\section{Materials and Methods}

A temperature control unit (manufactured by Sterling, Inc.) operating on tap water was utilized to provide a constant temperature closed loop heat source. With the immersion hardware installed, stainless steel plumbing allowed fluid flow past the evaporator. With the titanium clamshell hardware installed, flow through the clamshell arrangement could also be achieved. Maintaining an overpressure within the system by utilizing the building water supply enabled the closed loop heat source to operate at temperatures as high as $394 \mathrm{~K}$.

Titanium-water thermosyphons are being considered for use on the lunar surface owing to their high strength and low mass. Hence, titanium-water thermosyphons were manufactured in-house to support this work. Each was 1.27 $\mathrm{cm}$ in diameter and $74 \mathrm{~cm}$ in length. The material used was commercially pure (CP2) titanium having a $0.09 \mathrm{~cm}$ wall. A titanium screen wick was prepared for each, to line the evaporator wall section only. Each thermosyphon was charged with approximately 10 milliliters of deionized water followed by a two week burn in period before final crimping and welding. Care was taken to manufacture the thermosyphons in as identical a fashion as possible, including cutting the screen wick, installing the screen wick in the evaporator, charging the system with deionized water, burn in, crimping, and welding. For those thermosyphons destined for immersion testing, the evaporator sections were machined with different fin geometries (or no fins at all). Closed loop heat source water flow in the immersion chamber was along the length of the evaporator. For those thermosyphons destined for conduction testing, the evaporator sections were clamped into a titanium clamshell fixture machined to accept the evaporator section while utilizing different interface materials. A redundant clamping pressure was used for assembling the fixture by utilizing a digital torque wrench, and the torque applied was $24.8 \mathrm{~N} \cdot \mathrm{m}$. Closed loop heat source water flow in the clamshell fixture was through a gun-drilled section parallel to the axis of the evaporator. Figure 2 summarizes the various fin geometries. Table 1 summarizes the approximate surface area of the as-manufactured evaporators. Note: Given that the closed loop heat source circulated through one-half of the clamshell only, the areas in Table 1 for thermosyphon \#2 and \#10 represent the area in contact with the half of the clamshell through which water flowed. 


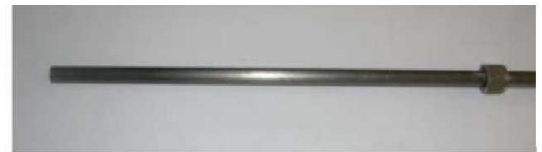

1) Plain Evaporator, 1.27 cm O.D., \#1

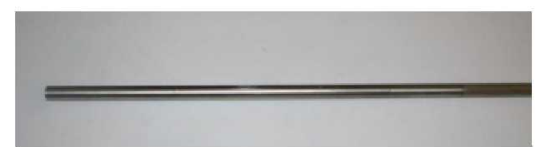

2) Polished Evaporator, $1.27 \mathrm{~cm}$ O.D., \#2

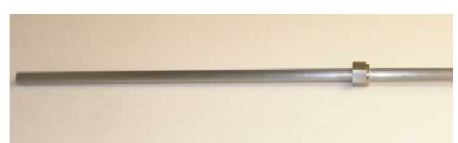

3) Plain Evaporator, 1.27 cm O.D., \#3

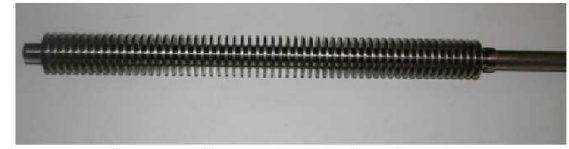

4) Tall Radial Fin, $2.54 \mathrm{~cm}$

O.D., \#4

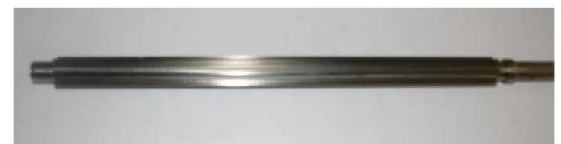

5) Low Axial Fin, six 0.32 cm fins, \#5

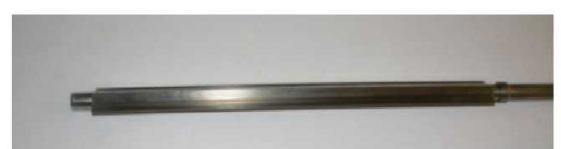

6) Two Axial Fin, two 0.64 cm fins, \#6

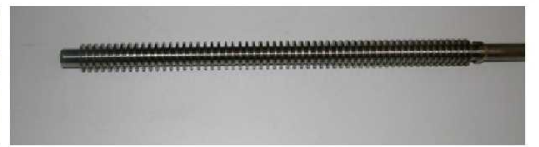

7) Short Radial Fin, $1.91 \mathrm{~cm}$

O.D., \#7

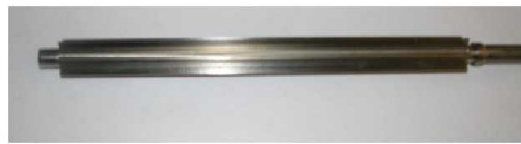

8) Tall Axial Fin, six $0.64 \mathrm{~cm}$ fins, \#8

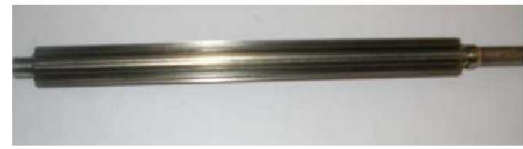

9) Tall Twelve Fin Axial, twelve $0.64 \mathrm{~cm}$ fins, \#9

10) Plain Evaporator, $1.27 \mathrm{~cm}$ O.D., full length view, \#10.

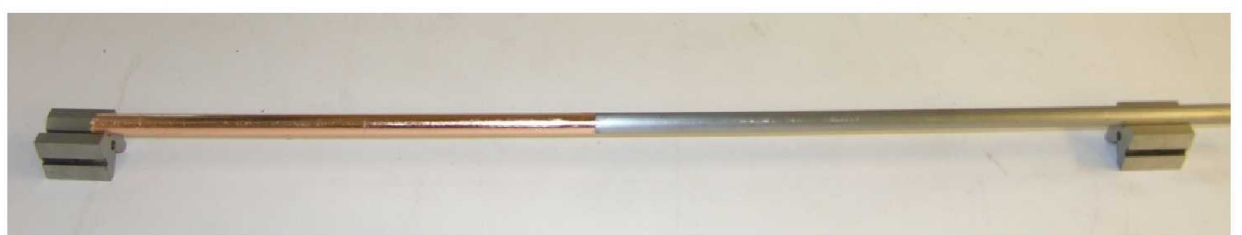

11) Evaporator covered with copper leaf, $1.27 \mathrm{~cm}$ O.D., full length view, \#11

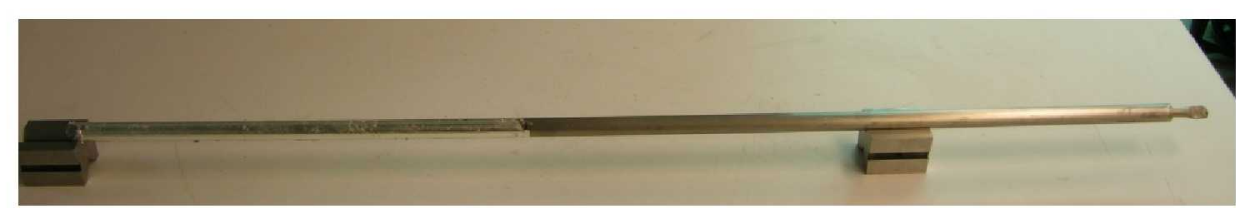

12) Evaporator covered with silver leaf, $1.27 \mathrm{~cm}$ O.D., full length view, $\# 12$

FIGURE 2. Photographs of the thermosyphon evaporators utilized here.

Table 1. Evaporator surface area.

\begin{tabular}{|c|c|}
\hline$\# 1, \# 3$ & $111 \mathrm{~cm}^{2}$ \\
\hline$\# 4$ & $310 \mathrm{~cm}^{2}$ \\
\hline$\# 5$ & $238 \mathrm{~cm}^{2}$ \\
\hline$\# 6$ & $231 \mathrm{~cm}^{2}$ \\
\hline$\# 7$ & $244 \mathrm{~cm}^{2}$ \\
\hline$\# 8$ & $345 \mathrm{~cm}^{2}$ \\
\hline$\# 9$ & $539 \mathrm{~cm}^{2}$ \\
\hline $\begin{array}{c}\# 2, \# 10, \# 11, \# 12 \\
\text { (installed in clamshell) }\end{array}$ \\
\hline
\end{tabular}

American Institute of Aeronautics and Astronautics 
A selection of interface materials were evaluated in the clamped configuration, selected based on high temperature durability, pliability, and availability. Two GrafTech International grafoil products were evaluated, eGRAF@ HITHERM ${ }^{\mathrm{TM}} 705$ and eGRAF® HITHERM ${ }^{\mathrm{TM}}$ 1205. The HT-705 has a typical through thickness thermal conductivity of $6.0 \mathrm{~W} / \mathrm{mK}$, while the HT-1205 has a through thickness thermal conductivity of $10 \mathrm{~W} / \mathrm{mK}$. Both grafoil products were plain, with no coatings or adhesives applied. One Aavid Thermalloy product was evaluated, Aavid Sil-Free ${ }^{\mathrm{TM}}$ thermal grease. Copper and silver leaf, were selected owing to their pliability. The two leaf products were purchased through an art supply house, and were simply wrapped around the evaporator at the time of installation. T-Mate ${ }^{\mathrm{TM}}$, a phase change product by Laird Technologies, was selected owing to its attractive phase change temperature in the range of 323 to $343 \mathrm{~K}$ combined with its maximum operating temperature of $398 \mathrm{~K}$. Table 2 presents a list of the different interface materials utilized in the clamshell configuration and the degree of contact at installation (tight or loose).

Table 2. Interface material utilized in the clamshell fixture.

\begin{tabular}{|c|c|}
\hline Tightly Clamped & Loosely Clamped \\
\hline Grafoil HT1205 & \\
\hline Grafoil HT705 & \\
\hline Aavid Thermalloy & Aavid Thermalloy \\
\hline Silver Leaf & \\
\hline Copper Leaf & \\
\hline T-Mate & \\
\hline No Interface & No Interface \\
\hline
\end{tabular}

A gas gap calorimeter was used to extract heat from the system utilizing helium in the gap between the thermosyphon condenser wall and the surrounding water jacket cold wall. Knowing the temperature difference across the calorimeter, along with the mass rate of flow and heat capacity of the water, allowed the wattage passing through the system to be calculated. With the thermosyphon insulated from its surroundings, and at steady state, the wattage extracted from the closed loop heat source, passing through the walls of the evaporator, carried to the condenser, passing through the walls of the condenser, and entering the gas gap calorimeter was equivalent. The system is illustrated schematically in Figure 3, and a photograph of the system is shown in Figure 4. A heated water loop provides infinite heat capacity to node 1 , either as an immersion chamber or as a titanium clamshell. Heat flows across interface 1 (with resistance $R_{1}$ ) to node 2 , the thermosyphon. Heat flows out of the thermosyphon through interface 2 (with resistance $R_{2}$ ) to node 3 , a gas gap calorimeter operated on water and instrumented with two thermocouples and a flow meter to provide $\dot{m} \mathrm{C}_{\mathrm{p}} \mathrm{dT}$. Helium fills the gap in the gas gap calorimeter, and $\mathrm{R}_{2}$ is assumed to be constant between all pipes. Equation 1, utilizing the gas gap calorimeter data, provides a measure of heat flow through the entire system

$$
\mathrm{Q}=\dot{m} \mathrm{C}_{\mathrm{p}} \mathrm{dT}
$$

where $Q$ is the calculated throughput in watts, $\dot{m}$ is the mass rate of flow, $C_{p}$ is the heat capacity of water, and dT is the temperature difference across the gas gap calorimeter. Temperature data at various other locations across the

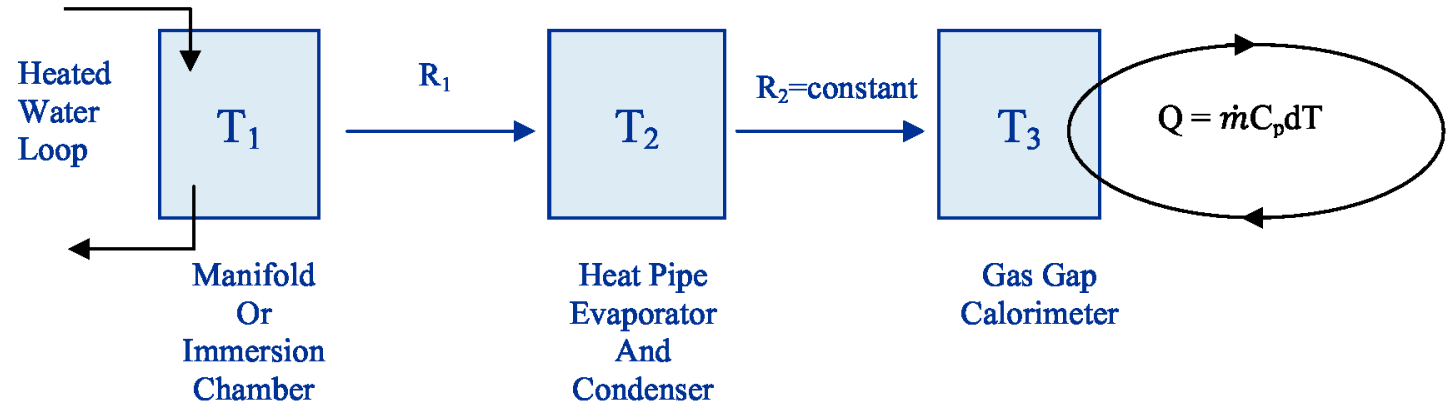

FIGURE 3. Heat flow from heated water loop, through thermosyphon, to gas gap calorimeter. 
system were also obtained utilizing a data acquisition system based on LabView@ software. Investigated here was the temperature of the closed loop heat source compared to the temperature of the evaporator wall. At steady state, this temperature difference, along with the wattage obtained from Equation 1, was utilized to calculate the thermal conductance through either the immersion interface or through the conduction interface utilizing Equation 2

$$
\mathrm{k} / \mathrm{L}=\mathrm{Q} /(\mathrm{A} \Delta \mathrm{T})
$$

where $\mathrm{k} / \mathrm{L}$ is the loop - evaporator interface conductance, $\Delta T$ is temperature difference between the closed loop heat source, and the evaporator $\left(T_{1}-T_{2}\right), Q$ is the wattage calculated from Equation 1, and $A$ is the surface area of the interface (as summarized in Table 1).
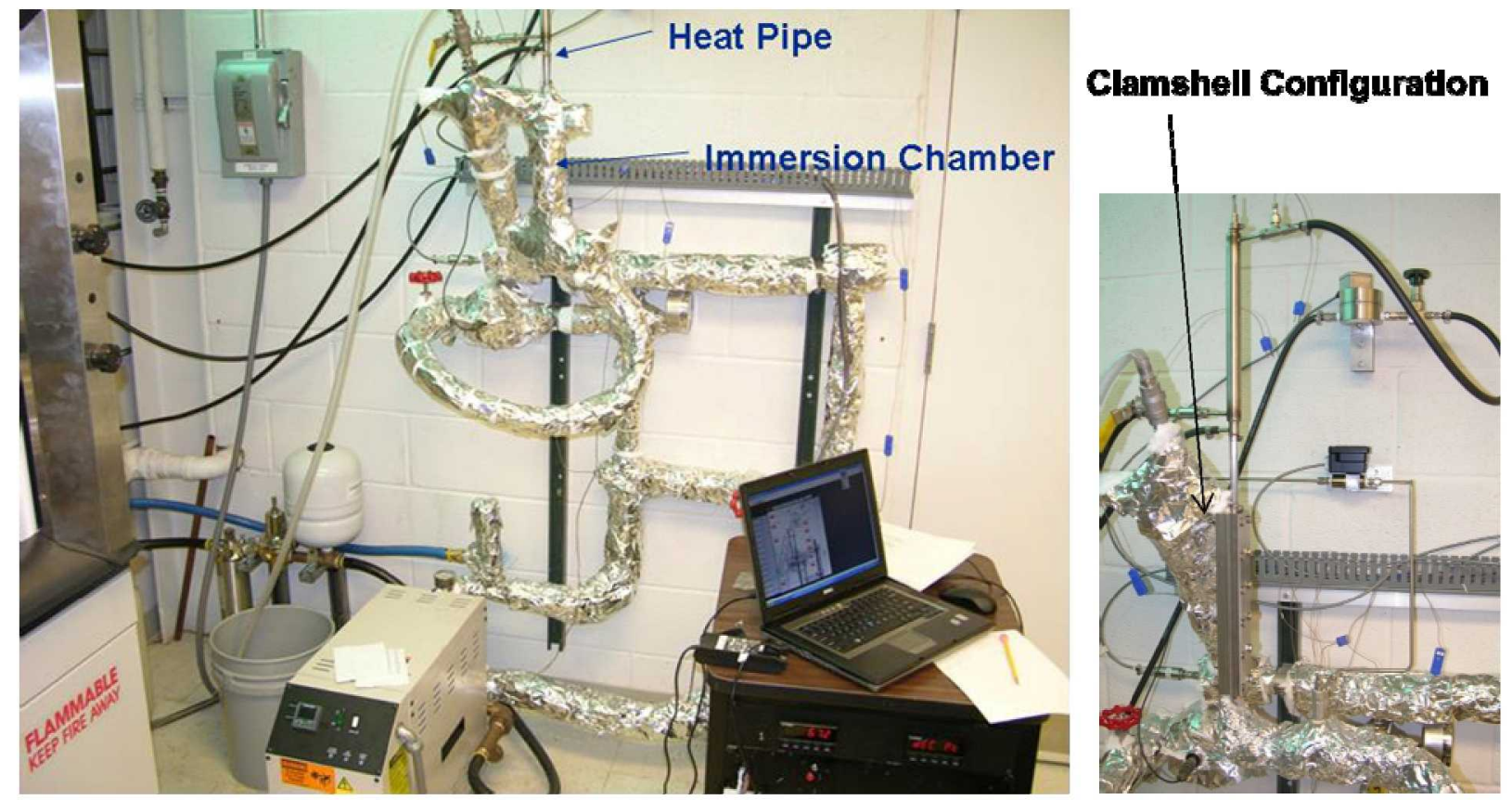

FIGURE 4. Thermal interface evaluation system.

Two thermocouples were utilized to record the temperature of the gas gap calorimeter water, to provide data for Equation 1. One thermocouple attached to the immersion chamber or clamshell fixture showed temperature at steady state, utilized to provide data for Equation 2. Three thermocouples were attached to the thermosyphon at various locations and were used to record the temperature along its length to confirm proper operation and the one closest to the evaporator was used to provide data for Equation 2. Steady state was indicated by no change in temperature during a fifteen minute time span.

\section{Results and Discussion}

Initial testing revealed little difference in system performance as a function of the flow of helium, calorimeter water, or water in the closed loop heat source, and the temperature drop in the closed loop heat source was negligible. Hence, helium flow was maintained at approximately 8 cubic centimeters per minute, calorimeter fluid flow was maintained at approximately 800 cubic centimeters per minute, and closed loop heat source water flow was maintained at approximately 30 liters per minute throughout all subsequent testing.

For each thermosyphon, the closed loop heat source system was allowed to reach steady state at temperatures of (in ascending order) $350,360,370,380,390$, and $394 \mathrm{~K}$. In general, steady state was reached for each temperature increment in a few tens of minutes. The last several data points at each temperature increment were averaged and utilized to calculate wattage and conductance. Figure 5 summarizes the thermal conductance through each interface as a function of temperature, as calculated according to Equation 2. 

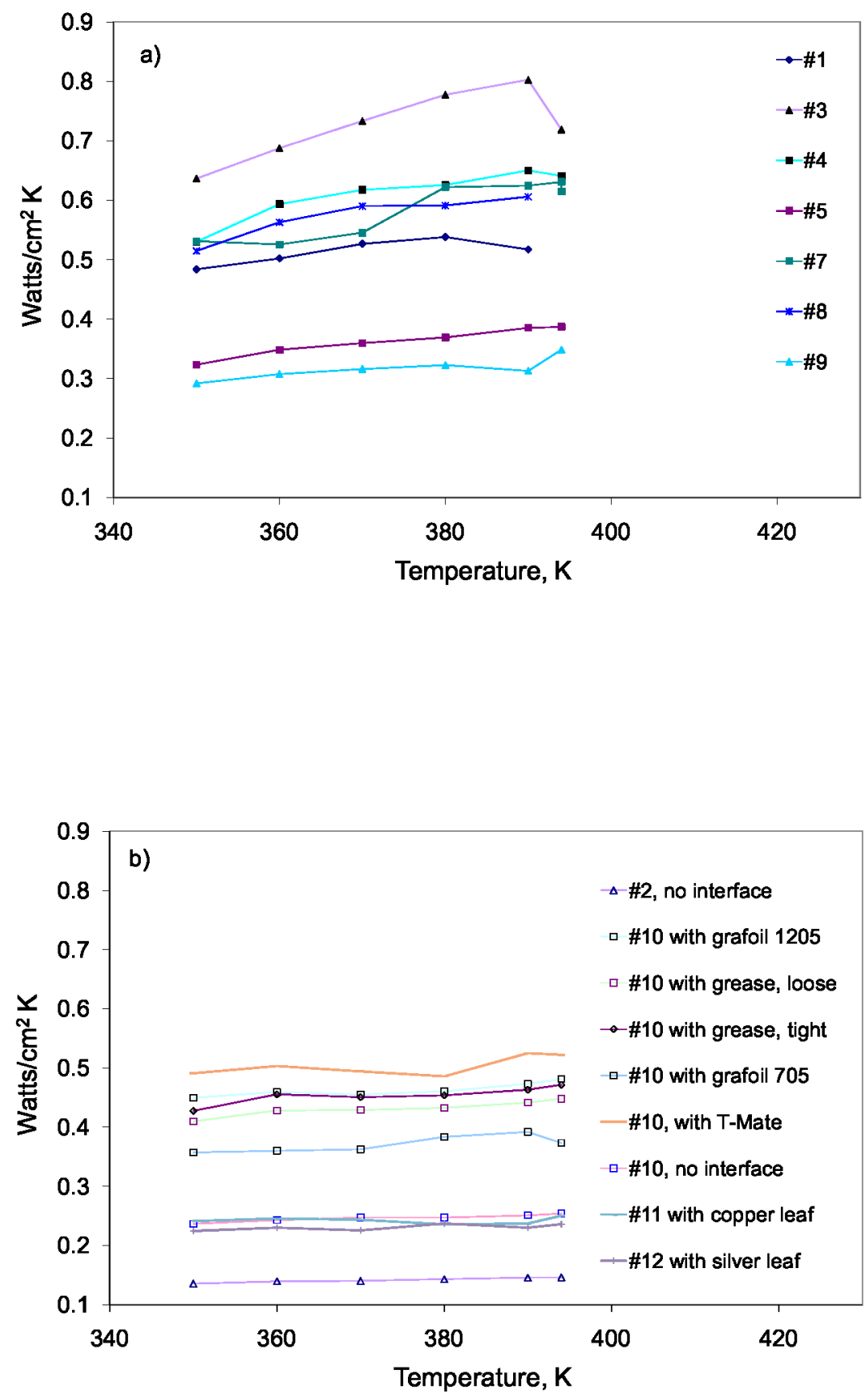

FIGURE 5. Thermal conductance versus temperature for thermosyphons tested: a) in the immersion mode, and b) in the clamped mode.

Thermosyphon \#3 had the best thermal conductance of all the immersion thermosyphons tested. Thermosyphon \#3 had no fins, and the exterior wall of the evaporator was purposely cleaned via abrasion (utilizing Scotch-Brite ${ }^{\mathrm{TM}}$ ) prior to installation in the immersion chamber. This observation is reminiscent of heat exchange enhanced by 
surface roughness. ${ }^{7}$ Thermosyphon \#1 was similarly installed. However, \#1 had an oily film on it after it was removed from the test fixture thought to come from the plumbing, an artifact of initial thermal interface evaluation facility operation. Thermosyphon \#6 leaked, hence, data from thermosyphon \#6 are not presented. All of the finned thermosyphons tested in immersion mode had less wattage throughput than thermosyphon \#3. Although all fins were integral to their respective evaporators because they were machined from a solid block of CP2 titanium and subsequently gun-drilled, their performance was limited by the relatively poor thermal conductivity of the titanium itself. Uncertainties brought about by thermosyphon construction variation are thought to be minimal owing to the care taken during manufacturing. T-Mate ${ }^{\mathrm{TM}}$ had the best thermal conductance of all the clamped thermosyphons tested, followed closely by grafoil 1205 and Aavid Sil-Free ${ }^{\mathrm{TM}}$ thermal grease. Grafoil 705, copper, silver, and plain were intermediate, and the polished heat pipe evaporator loosely clamped in the clamshell fixture was worst. Uncertainties brought about by thermosyphon construction variation are mostly absent in the clamshell configuration because much of the data were obtained utilizing the same thermosyphon, i.e. thermosyphon \#10.

\section{Future Work}

Pressure drop across the closed loop heat source is a concern. Future work will investigate alternative bonding methods, materials, and configurations, including: Poco graphite, silver-filled epoxy, and aluminum silicon carbide (AlSiC) composite. The benefits of a bonded configuration are worthy of consideration, including: compact evaporator positioning and a low pressure gradient through the closed loop heat source. Brazing evaporators to AlSiC may have interesting results because the AlSiC has a coefficient of thermal expansion similar to titanium. Evaluating the impact of dust on radiators is an ongoing area of interest. ${ }^{8}$

\section{Conclusions}

A thermal interface evaluation system was designed and built to study the thermal conductance across immersed and clamped interfaces. A closed loop heat source was utilized to power immersed and clamped thermosyphons having various geometry and interface materials. Wattage through the thermosyphons was measured utilizing a gas gap calorimeter, and at steady state, the wattage, temperature distribution, and evaporator surface area were utilized to calculate thermal conductance.

From the suite of immersed interfaces, an evaporator having no fins and purposely cleaned via abrasion had the best thermal conductance compared to others. Immersing the evaporator in water provides intimate contact between the loop heat source fluid and the evaporator wall, maximizing heat flow through the wall of the evaporator. From the suite of clamped interfaces, T-Mate ${ }^{\mathrm{TM}}$, grafoil 1205, and Aavid Sil-Free ${ }^{\mathrm{TM}}$ thermal grease responded well, with other interface materials having either intermediate or poor conductance.

Planned for the future is an effort to study bonding evaporators to Poco graphite with silver-filled epoxy, and brazing evaporators to $\mathrm{AlSiC}$, which may offer compact evaporator positioning and a low pressure gradient through the closed loop heat source.

\section{Acknowledgments}

The authors thank NASA's Exploration Technology Development Program for their support of this work.

\section{References}

${ }^{1}$ National Aeronautics and Space Administration, " "Exploration Systems Architecture Study-Final Report," NASA-TM2005-214062, NASA Headquarters, Washington, DC, pp 80-81, November 2005.

${ }^{2}$ Moore, C.L., and Peri, F., "The Exploration Technology Development Program," $45^{\text {th }}$ AIAA Aerospace Sciences Meeting and Exhibit, Reno, NV, 2007, AIAA-2007-136.

${ }^{3}$ Werner, J. and Mason, L., "An Affordable Test Approach for Lunar Fission Surface Power Systems," Space Technology and Applications International Forum - STAIF 2008, edited by M.S. El-Genk, Albuquerque, NM, pp 301-306, 2008.

${ }^{4}$ Mason, L., "Recent Advances in Power Conversion and Heat Rejection Technology for Fission Surface Power," Proceedings of Nuclear and Emerging Technologies for Space 2009, Atlanta, GA, 2009, Paper 204298.

${ }^{5}$ Bernhard, R.P., Christiansen, E.L., and Kessler, D.E., "Orbital Debris as Detected on Exposed Spacecraft," Int. J. Impact Eng., Vol. 20, pp 111-120, 1997.

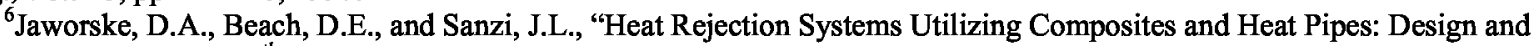
Performance Testing," $5^{\text {th }}$ International Energy Conversion Engineering Conference, St. Louis, MO, 2007, AIAA $2007-4822$. 2001.

${ }^{7}$ Kreith, F. and Bohn, M.S., Principles of Heat Transfer, $6{ }^{\text {th }}$ Edition, Thompson Learning, Ontario, Canada, pp 391-393., 
${ }^{8}$ Gaier, J.R., Siamidis, J., Panko, S.R., Rogers, K.J., and Larkin, E.M.G., "The Effect of Simulated Lunar Dust on the Absorptivity, Emissivity, and Operating Temperature on AZ-93 and Ag/FEP Thermal Control Surfaces," NASA-TM-2008215492, NASA Glenn Research Center, December 2008. 